\title{
BMJ Open Prevalence of liver fibrosis and associated risk factors in the Korean general population: a retrospective cross-sectional study
}

\author{
Eun-Hee Nah (D) , ${ }^{1}$ Seon Cho, ${ }^{1}$ Suyoung Kim, ${ }^{1}$ Jieun Chu, ${ }^{1}$ Eunjoo Kwon, ${ }^{1}$ \\ Han-Ik Cho ${ }^{2}$
}

To cite: Nah E-H, Cho S, Kim S, et al. Prevalence of liver fibrosis and associated risk factors in the Korean general population: a retrospective cross-sectional study. BMJ Open 2021;11:e046529. doi:10.1136/ bmjopen-2020-046529

- Prepublication history for this paper is available online. To view these files, please visit the journal online (http://dx.doi org/10.1136/bmjopen-2020046529).

Received 05 November 2020 Revised 09 March 2021 Accepted 09 March 2021

Check for updates

(C) Author(s) (or their employer(s)) 2021. Re-use permitted under CC BY-NC. No commercial re-use. See rights and permissions. Published by BMJ.

${ }^{1}$ Health Promotion Research Institute, Korea Association of Health Promotion, Seoul, South Korea

${ }^{2}$ MEDIcheck LAB, Korea

Association of Health Promotion, Seoul, South Korea

Correspondence to

Dr Eun-Hee Nah;

cellonah@hanmail.net

\section{ABSTRACT}

Objectives The health burden of chronic liver disease is increasing worldwide. Its main histological consequence is liver fibrosis, and eventually cirrhosis. This process is rarely diagnosed at the pre-cirrhotic stage due to it being asymptomatic. Little is known about the prevalence of liver fibrosis and associated risk factors in the general population. The aims of this study were to determine the prevalence and distribution of liver fibrosis using magnetic resonance elastography (MRE), as well as the risk factors associated with liver fibrosis in the asymptomatic general population.

Design, setting and participants This cross-sectional retrospective study consecutively selected subjects who underwent health check-ups including MRE at 13 health promotion centres in Korea between 2018 and 2020. Liver fibrosis was estimated using MRE with cut-off values for significant and advanced liver fibrosis of 2.90 and $3.60 \mathrm{kPa}$, respectively.

Primary and secondary outcome measures The $\mathrm{X}^{2}$ test was used to compare the prevalence of liver fibrosis according to sex and age groups. Multivariable logistic regression analyses were performed to identify the factors for significant and advanced liver fibrosis.

Results Among the 8183 subjects, 778 (9.5\%) had $\geq$ significant fibrosis ( $\geq 2.9 \mathrm{kPa}$ ), which included 214 (2.6\%) subjects with $\geq$ advanced fibrosis $(\geq 3.6 \mathrm{kPa}$ ). Multivariable analysis revealed that liver fibrosis was associated with age $(\mathrm{OR}=1.34,95 \% \mathrm{Cl}=1.18$ to 1.51$)$, male sex $(\mathrm{OR}=3.18$, $95 \% \mathrm{Cl}=1.97$ to 5.13$)$, diabetes $(\mathrm{OR}=2.43,95 \% \mathrm{Cl}=1.8$ to 3.28), $\mathrm{HBsAg}$ positivity ( $\mathrm{OR}=3.49,95 \% \mathrm{Cl}=2.55$ to 4.79 ), abnormal liver function test $(\mathrm{OR}=1.9,95 \% \mathrm{Cl}=1.49$ to 2.42) and obesity $(\mathrm{OR}=1.77,95 \% \mathrm{Cl}=1.35$ to 2.32 ) (all $\mathrm{p}<0.001)$, as well as metabolic syndrome $(\mathrm{OR}=1.4,95 \%$ $\mathrm{Cl}=1.05$ to 1.87$)(\mathrm{p}=0.024)$.

Conclusions The prevalence of significant or more liver fibrosis was high in the Korean general population and much higher among individuals with risk factors. This suggests that screening of liver fibrosis should be considered in general population, especially among highrisk groups.

\section{INTRODUCTION}

Cirrhosis is the 12th most common cause of death in the world. ${ }^{1}$ The major histological
Strengths and limitations of this study

- The strength of this study lies in enrolling a large number of subjects $(\mathrm{N}=8183)$ and wide range of subjects' age (range 19-85 years).

- Liver fibrosis was estimated using the magnetic resonance elastography, which is a reliable noninvasive method for defining liver fibrosis in health check-ups.

- This study involves chronic liver disease, which is an important public health concern.

- This study had a cross-sectional design, and so further studies are needed to track the changes in liver fibrosis after applying interventions and to monitor long-term outcomes.

consequence of chronic liver disease is the deposition of collagen fibres that causes progressive liver fibrosis and eventually cirrhosis. $^{2} 3$ Since chronic liver disease progresses to cirrhosis very slowly and asymptomatically, the disease is rarely diagnosed in the early stage of the liver fibrosis. The associated mortality and morbidity rates increase exponentially once cirrhosis develops, ${ }^{4}$ and so chronic liver disease should ideally be diagnosed before cirrhosis develops or during the early stage of liver fibrosis, particularly in the community setting. ${ }^{5}$ The ability to accurately diagnose liver fibrosis early would allow identification of causal factors responsible for liver fibrosis and subsequent application of specific interventions. ${ }^{6}$

Epidemiological studies assessing the prevalence of liver fibrosis and the associated risk factors in the general population are essential to designing effective screening strategies for the early diagnosis of liver fibrosis. However, few studies have focused on the prevalence of liver fibrosis and the associated risk factors in the general population. Many studies have analysed liver biopsy results in specific 
populations. However, a liver biopsy is an invasive procedure and so the subjects in such studies are rarely representative of the at-risk general population.

Non-invasive techniques have been developed recently to replace the need for liver biopsy. One of these techniques is magnetic resonance elastography (MRE), which findings are strongly associated with the histological stages of liver fibrosis. ${ }^{7-10}$ However, another limitation of previous studies is that they have investigated the prevalence of liver fibrosis and associated risk factors only in restricted age groups,${ }^{11}{ }^{12}$ selected disease groups such as type 2 diabetes mellitus $(\mathrm{T} 2 \mathrm{DM})^{13}$ or alcoholic liver disease. $^{14}$

Therefore, the aims of this study were to determine the prevalence and distribution of liver fibrosis as estimated using MRE, as well as the factors associated with liver fibrosis in the Korean general population.

\section{METHODS}

\section{Subjects}

This cross-sectional retrospective study consecutively selected subjects who underwent health check-up including MRE at 13 health promotion centres in Korea between January 2018 and June 2020. The 13 health promotion centres belong to the Korea Association of Health Promotion. The 16 health promotion centres belong to the Korea Association of Health Promotion. Korea has a national health insurance system (NHIS) that covers the entire population of Korea and provides biennial medical examinations. These 16 health promotion centres perform about $10 \%$ of the health check-ups that are provided by the NHIS in Korea. Among the 16 health promotion centres, the 13 health promotion centres that have been installed MRE were selected for the present study (figure 1). The self-reported personal medical history, subjective symptoms and signs, and lifestyle information were obtained from all participants at the time of health check-ups. Their medical records were also reviewed. The exclusion criteria were a history of malignancy, stroke or myocardial infarction.

Out of 8300 eligible subjects, 8183 were analysed (figure 2). Excessive alcohol consumption was defined as drinking $\geq 14$ and $\geq 7$ standard units/week in men and women, respectively. ${ }^{15}$ Informed consent was waived as deidentified data and retrieved data from the past data of health check-ups were used.

\section{MRE examination}

All MRE examinations were performed on either MRE hardware (GE Healthcare, Waukesha, Wisconsin, USA) with a 1.5-T imaging system or 1.5-T whole-body magnetic resonance unit (Gyroscan Intera, Philips Medical Systems, Best, the Netherlands) using a four-element torso coil. The two-dimensional MRE protocols used were similar to those described previously in the literature. ${ }^{16} 17$ The liver stiffness (LS) values of the hepatic parenchyma were measured using MRE by placing four regions of interest

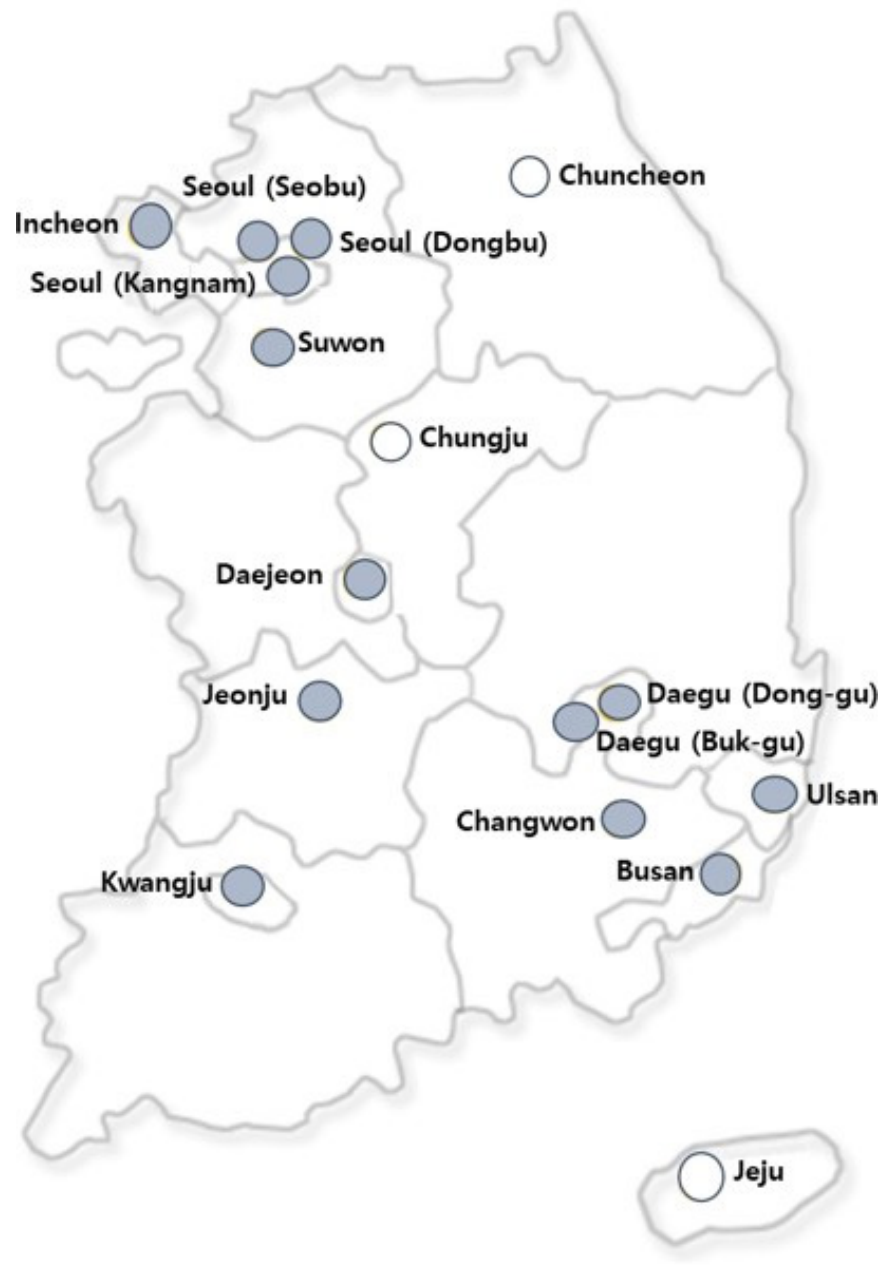

Figure 1 Map showing the location of 16 health promotion centres of the Korea Association of Health Promotion. Shading shows 13 health promotion centres selected in the study.

(ROIs) on the elastogram. ROIs were determined by the attending radiologists. All ROIs were drawn in the area indicated to have a high confidence and good signalto-noise ratio, with stiffness outliers excluded on the confidence map ${ }^{18}$ and then copied to the corresponding position on stiffness maps that provided stiffness values in kilopascals. After reconfirming whether the ROIs were adequately placed in the right liver lobe, the LS value was calculated as the median value in multiple ROIs.

The cut-off values for liver fibrosis using MRE in the current study were 1.94, 2.90 and $3.6 \mathrm{kPa}$ for fibrosis stage F1 (mild fibrosis), F2 (significant fibrosis) and $\geq$ F3 (advanced fibrosis), respectively. ${ }^{19-21}$ The cut-offs of abnormal aspartate transaminase (AST) and alanine aminotransferase (ALT) for both men and women were defined as $>33 \mathrm{U} / \mathrm{L}$ and $>38 \mathrm{U} / \mathrm{L}$, respectively. ${ }^{22}$

\section{Laboratory measurements}

Venous blood was drawn after an overnight fast for health check-ups that included the complete blood count (CBC) and biochemical measurements. The CBC and biochemical parameters were measured using the Sysmex 
8,300 examinees who received health checkup including MRE

Eligible subjects $(n=8,183)$

Analysed $(n=8,183)$

Figure 2 Flow chart of the study. MRE, magnetic resonance elastography.

XE-2100D analyser (Sysmex, Kobe, Japan) and the Hitachi 7600 analyser (Hitachi, Tokyo, Japan), respectively.

\section{Statistical analysis}

Statistical analyses were performed using SAS V.9.4 (SAS Institute). Data are presented as mean (SD) or frequency (percentage) values. The $\mathrm{X}^{2}$ test was used to compare the prevalence of liver fibrosis according to sex and age groups. Differences among the four liver fibrosis groups were analysed using one-way analysis of variance for means, and the $\mathrm{X}^{2}$ test and Fisher's exact test for frequencies. Univariate (crude) and multivariable (adjusted) logistic regression analyses were performed to identify the factors contributing to significant and advanced liver fibrosis. A $p$ value of $<0.05$ was considered statistically significant.

\section{Patient and public involvement}

Patients were not involved in the recruitment to and conduct of the study. Results will be disseminated to study participants through annual information events.

\section{RESULTS}

\section{Characteristics of study subjects}

The characteristics of the 8183 study subjects are listed in table 1 . Mean age of the study subjects was $46.9 \pm 10.5$ years (range $28-82$ years). The study subjects included 6489 men $(79.3 \%)$. The age distribution was as follows: $335(4.1 \%)$ aged $<30$ years, $1785(21.8 \%)$ aged $30-39$ years, $2700(33.0 \%)$ aged $40-49$ years, $2241(27.4 \%)$ aged 50-59 years, $939(11.5 \%)$ aged $60-69$ years, and 183 $(2.2 \%)$ aged $\geq 70$ years. The mean body mass index (BMI) was $24.8 \mathrm{~kg} / \mathrm{m}^{2}$. The prevalence rates of T2DM, hypertension, metabolic syndrome and fatty liver diagnosed by ultrasonography were $11.2 \%, 16.4 \%, 21.9 \%$ and $38.9 \%$, respectively.

\begin{tabular}{|c|c|}
\hline & Total \\
\hline Variables & $(\mathrm{N}=8183)$ \\
\hline Age, year & $47.2 \pm 10.8$ \\
\hline Sex, male Male & 6489 (79.3) \\
\hline BMI, $\mathrm{kg} / \mathrm{m}^{2}$ & $24.8 \pm 3.3$ \\
\hline Overweight, $\geq 23$ to $<25 \mathrm{~kg} / \mathrm{m}^{2}$ & $2010(26)$ \\
\hline Obese, $\geq 25 \mathrm{~kg} / \mathrm{m}^{2}$ & $3531(45.6)$ \\
\hline Abdominal obesity ${ }^{*}$ & $2567(32.4)$ \\
\hline Diabetes & 899 (11.2) \\
\hline Hypertension & $1313(16.4)$ \\
\hline Metabolic syndrome & $1727(21.9)$ \\
\hline Excessive alcohol consumption & $1958(36.9)$ \\
\hline Current or former smoking & $3164(59.5)$ \\
\hline Fatty liver by ultrasonography & $3182(38.9)$ \\
\hline PLT count,$\times 10^{9} / \mathrm{L}$ & $245.3 \pm 53.5$ \\
\hline Albumin, g/dL & $4.52 \pm 0.28$ \\
\hline AST, U/L & $31.4 \pm 32.8$ \\
\hline ALT, U/L & $33.5 \pm 46.3$ \\
\hline GGT, U/L & $55.5 \pm 78.1$ \\
\hline $\mathrm{AST}$ and/or $\mathrm{ALT}>\mathrm{ULN}^{\dagger}$ & $2487(31)$ \\
\hline $\mathrm{FBS}, \mathrm{mg} / \mathrm{dL}$ & $100.0 \pm 21.9$ \\
\hline $\mathrm{HbA1c} \%$ & $5.8 \pm 0.8$ \\
\hline $\mathrm{TC}, \mathrm{mg} / \mathrm{dL}$ & $200.4 \pm 38.5$ \\
\hline $\mathrm{TG}, \mathrm{mg} / \mathrm{dL}$ & $144.8 \pm 117$ \\
\hline HDL cholesterol, mg/dL & $53.1 \pm 13$ \\
\hline LDL cholesterol, mg/dL & $118.7 \pm 35.2$ \\
\hline HBs Ag positivity & $493(8.6)$ \\
\hline Anti-HCV positivity & $11(0.3)$ \\
\hline \multicolumn{2}{|l|}{ magnetic resonance elastography } \\
\hline Normal, $<1.94 \mathrm{kPa}$ & $1631(19.9)$ \\
\hline Mild fibrosis, $1.94-2.90 \mathrm{kPa}$ & $5774(70.6)$ \\
\hline Significant fibrosis, $2.91-3.59 \mathrm{kPa}$ & $564(6.9)$ \\
\hline Advanced fibrosis, $\geq 3.60 \mathrm{kPa}$ & $214(2.6)$ \\
\hline
\end{tabular}

Data are mean \pm SD or $\mathrm{N}(\%)$ values.

Frequencies might not add up to $100 \%$ due to missing data.

*Abdominal obesity: $\geq 90 \mathrm{~cm}$ for men and $\geq 85 \mathrm{~cm}$ for women. †ULN was $33 \mathrm{U} / \mathrm{L}$ for AST and $38 \mathrm{U} / \mathrm{L}$ for ALT.

ALT, alanine aminotransferase; AST, aspartate transaminase; BMI, body mass index; FBS, fasting blood sugar; GGT, gamma glutamyl transpeptidase; $\mathrm{HbA1c}$, glycated haemoglobin; HCV, hepatitis $\mathrm{C}$ virus; HDL, high-density lipoprotein; LDL, low-density lipoprotein; PLT, platelet; TC, total cholesterol; TG, triglycerides; ULN, upper limit of normal.

\section{Distribution of liver fibrosis values}

The distribution of liver fibrosis values as assessed using MRE in the study population is shown in figure 3 . The overall LS was $2.34 \pm 0.58 \mathrm{kPa}$, with a median of $2.27 \mathrm{kPa}$ (range $=0.47-9.55 \mathrm{kPa})$. Among the 8183 subjects, 1631 (19.9\%), $5774(70.6 \%), 564(6.9 \%)$ and $214(2.6 \%)$ had 


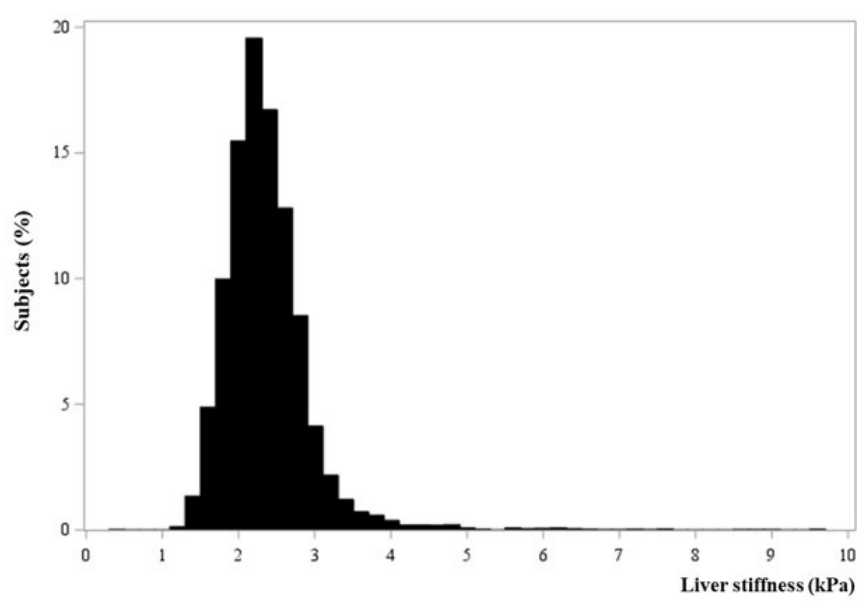

Figure 3 Distribution of liver fibrosis as measured using MRE among the study subjects. MRE, magnetic resonance elastography.

normal LS, mild fibrosis, significant fibrosis and advanced fibrosis, respectively (table 1 ).

\section{Prevalence of $\geq$ significant liver fibrosis according to age and} sex

The prevalence rate of $\geq$ significant liver fibrosis according to age and sex was summarised in table 2. The overall prevalence of $\geq$ significant liver fibrosis in the population was $9.5 \%(95 \% \mathrm{CI}=8.9 \%$ to $10.1 \%): 10.6 \%(95 \%$ $\mathrm{CI}=9.8 \%$ to $11.3 \%)$ for men and $5.4 \%(95 \% \mathrm{CI}=4.3 \%$ to $6.5 \%)$ for women. The prevalence rates of liver fibrosis increased rapidly with age in men and women from their 40 s and 50s, respectively. In each age group, the prevalence of $\geq$ significant liver fibrosis was higher in men than in women. The prevalence of $\geq$ significant liver fibrosis in both sexes increased gradually with age, reaching $15.3 \%$ among those aged $\geq 70$ years.

\section{Clinical and laboratory characteristics of study subjects according to liver fibrosis stage using MRE}

The prevalence rates of obesity, T2DM, hypertension, metabolic syndrome, HBsAg positivity and fatty liver were significantly higher in subjects with higher liver fibrosis stages (all $\mathrm{p}<0.001$ ) (table 3). Those with significant or advanced fibrosis (stage $\geq \mathrm{F} 2$ ) were predominantly men and had higher BMI, AST, ALT, gamma glutamyl transpeptidase, fasting blood sugar and triglyceride levels compared with subjects with normal LS (stage F0) $(\mathrm{p}<0.001)$ (table 4).

\section{Factors associated with liver fibrosis}

In a univariate model, older age, male sex, current or former smoking, obesity, hypertension, dyslipidaemia, T2DM, fatty liver, abnormal liver function test (LFT), HBsAg positivity and metabolic syndrome were associated with $\geq$ significant liver fibrosis (all $\mathrm{p}<0.001$ ). In multivariable analysis, age $(\mathrm{OR}=1.34,95 \% \mathrm{CI}=1.18$ to 1.51$)$, male sex $(\mathrm{OR}=3.18,95 \% \mathrm{CI}=1.97$ to 5.13$)$, T2DM $\quad(\mathrm{OR}=2.43$,

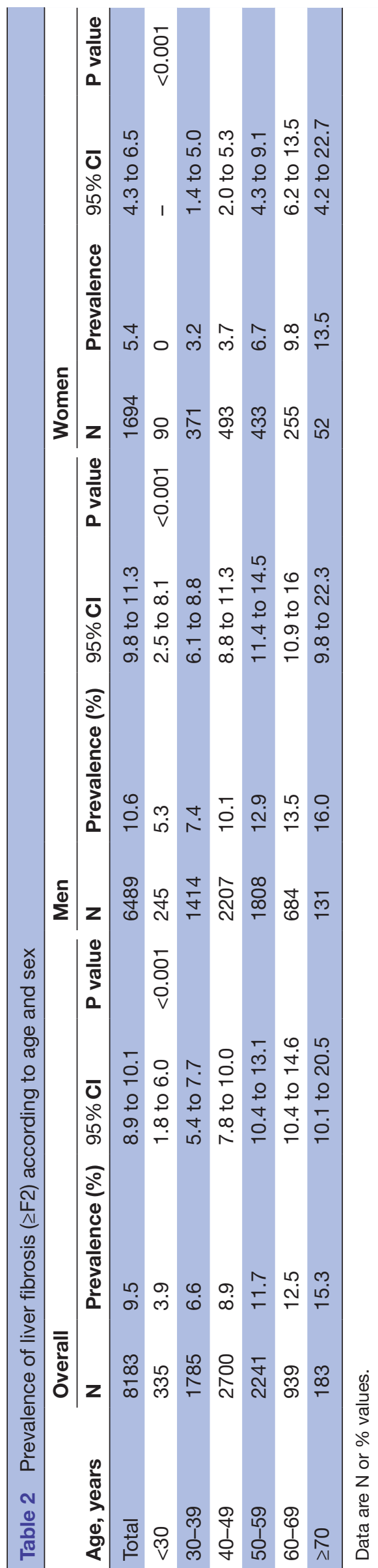


Table 3 Clinical and laboratory characteristics of study subjects according to liver fibrosis category using MRE

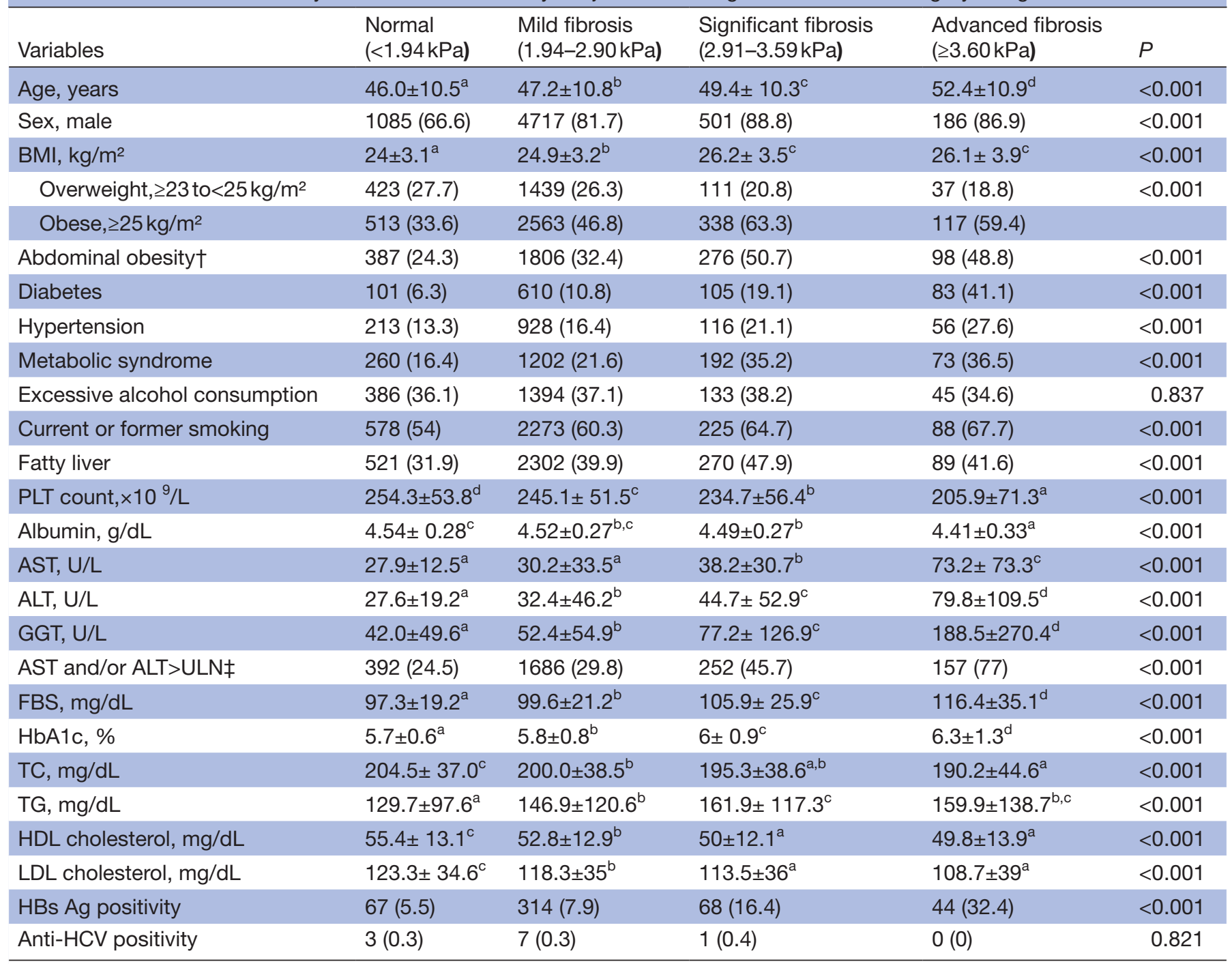

Data are mean \pm SD or $\mathrm{N}(\%)$ values.

Frequencies might not add up to $100 \%$ due to missing data.

a,b,c,d: Different letters indicate a significant difference between groups based on Scheffe's multiple-comparisons test.

${ }^{*} P$ values were derived from one-way ANOVA, the $X^{2}$ test and Fisher's exact test.

$\dagger$ Abdominal obesity: $\geq 90 \mathrm{~cm}$ for men and $\geq 85 \mathrm{~cm}$ for women.

‡ULN was $33 \mathrm{U} / \mathrm{L}$ for AST and $38 \mathrm{U} / \mathrm{L}$ for ALT.

ALT, alanine aminotransferase; ANOVA, analysis of variance; AST, aspartate transaminase; BMI, body mass index; FBS, fasting blood sugar; GGT, gamma glutamyl transpeptidase; HbA1c, glycated haemoglobin; HCV, hepatitis C virus; HDL, high-density lipoprotein; LDL, low-density lipoprotein; MRE, magnetic resonance elastography; PLT, platelet; TC, total cholesterol; TG, triglycerides; ULN, upper limit of normal.

$95 \% \mathrm{CI}=1.8$ to 3.28$)$, $\mathrm{HBsAg}$ positivity $(\mathrm{OR}=3.49,95 \%$ $\mathrm{CI}=2.55$ to 4.79$)$, abnormal LFT $(\mathrm{OR}=1.9,95 \% \mathrm{CI}=1.49$ to 2.42 ) and obesity ( $\mathrm{OR}=1.77,95 \% \mathrm{CI}=1.35$ to 2.32$)$ (all $\mathrm{p}<0.001)$, as well as metabolic syndrome $(\mathrm{OR}=1.4$, $95 \% \mathrm{CI}=1.05$ to 1.87$) \quad(\mathrm{p}=0.024)$ were associated with significant liver fibrosis. The risk factors associated with advanced liver fibrosis were older age $(\mathrm{OR}=1.39$, $95 \% \mathrm{CI}=1.09$ to 1.79$) \quad(\mathrm{p}=0.009), \mathrm{T} 2 \mathrm{DM} \quad(\mathrm{OR}=4.37,95 \%$ $\mathrm{CI}=2.56$ to 7.45$), \mathrm{HBsAg}$ positivity $(\mathrm{OR}=7.27,95 \% \mathrm{CI}=4.32$ to 12.25$)$ and abnormal LFT $(\mathrm{OR}=5.3,95 \% \mathrm{CI}=3.15$ to 8.93 (all $\mathrm{p}<0.001$ ). While current or former smoking, hypertension, dyslipidaemia and fatty liver were associated with $\geq$ significant liver fibrosis in a univariate model, these associations disappeared in the multivariable model (table 5).

\section{Prevalence rates of liver fibrosis in the risk group of liver fibrosis}

The prevalence rates of $\geq$ significant liver fibrosis in different risk groups are shown in figure 4 . The prevalence rates of $\geq$ significant liver fibrosis were $22.4 \%$, $20.9 \%, 16.5 \%, 15.3 \%, 12.9 \%$ and $11.3 \%$ among subjects with HBsAg positivity, diabetes mellitus, abnormal LFT, metabolic syndrome, obesity and fatty liver, respectively (figure 4). 
Table 4 Clinical characteristics of study subjects with and without significant and advanced liver fibrosis

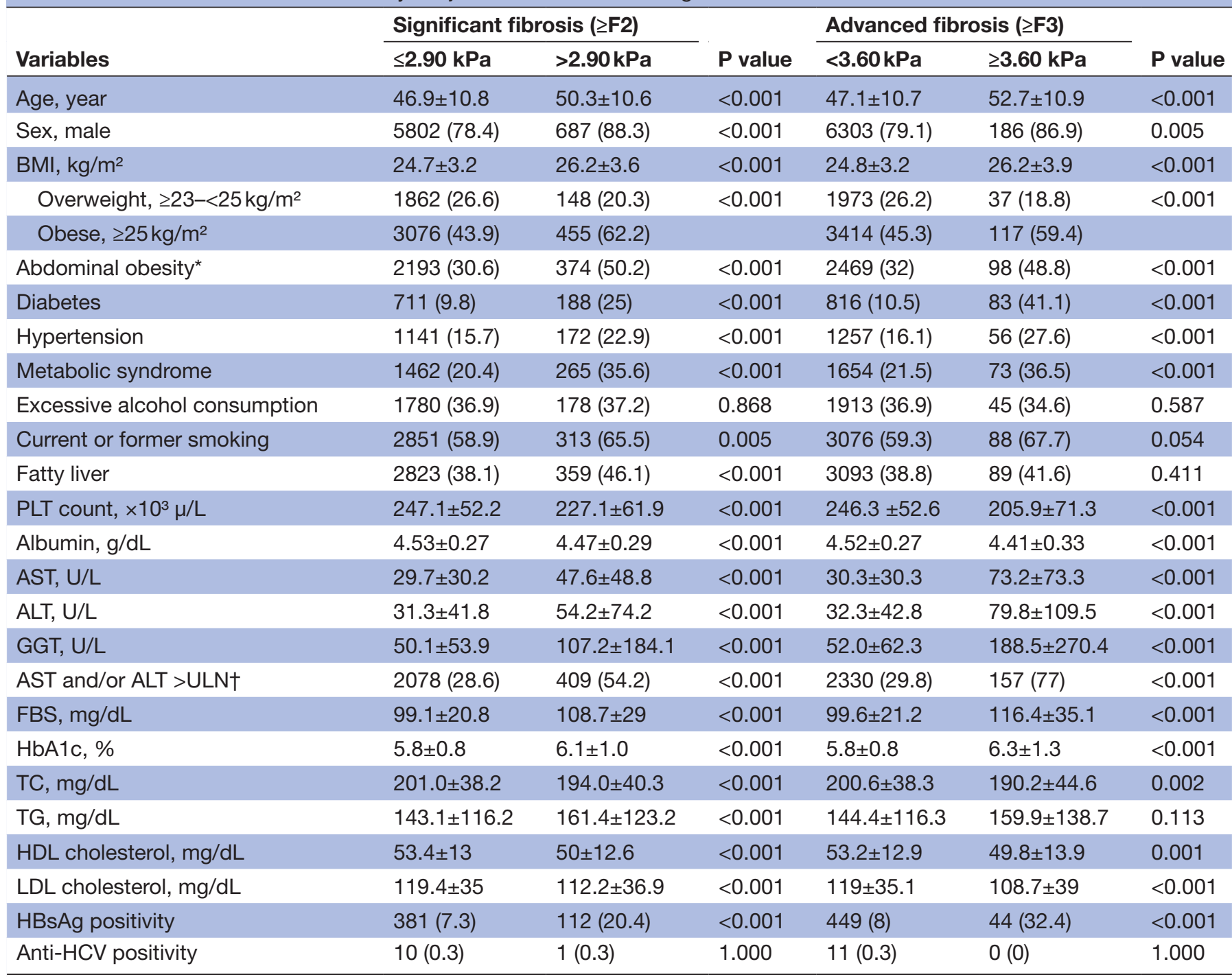

Data are mean \pm SD or $\mathrm{N}(\%)$ values.

Frequencies might not add up to $100 \%$ due to missing data.

$P$ values for the t-test, the $X^{2}$ test and Fisher's exact test.

*Abdominal obesity: $\geq 90 \mathrm{~cm}$ for men and $\geq 85 \mathrm{~cm}$ for women.

†ULN was $33 \mathrm{U} / \mathrm{L}$ for AST and $38 \mathrm{U} / \mathrm{L}$ for ALT.

ALT, alanine aminotransferase; AST, aspartate transaminase; BMI, body mass index; FBS, fasting blood sugar; GGT, gamma glutamyl transpeptidase; HbA1c, glycated haemoglobin; HCV, hepatitis C virus; HDL, high-density lipoprotein; LDL, low-density lipoprotein; PLT, platelet; TC, total cholesterol; TG, triglycerides; ULN, upper limit of normal.

\section{DISCUSSION}

This study found that the prevalence of clinically significant liver fibrosis as estimated using MRE was high (9.5\%) in the general population, and much higher among individuals with risk factors such as older age, male sex, HBsAg positivity, abnormal LFTs, T2DM, obesity and metabolic syndrome in the community setting. This study had the following strengths: (1) enrolling a large number of subjects ( $\mathrm{N}=8183)$; (2) using the MRE, which is a reliable non-invasive method for defining liver fibrosis in health check-ups; and (3) involving chronic liver disease, which is an important public health concern.

There have been only a few reports of the results of screening for liver fibrosis in the general population, with the prevalence of liver fibrosis ranging from $2.0 \%$ to $27 \% .^{11131423}$ All of these studies used transient elastography (TE) to estimate liver fibrosis, but the prevalence varied depending on the LS threshold, the characteristics of the study subjects and the estimated outcome of liver fibrosis. In a Europe-based study, ${ }^{24}$ the estimated prevalence rates were $9.0 \%, 5.8 \%$ and $3.6 \%$ for TE cutoffs of $\geq 6.8, \geq 8.0$ and $\geq 9.0 \mathrm{kPa}$, respectively. In a study from France, ${ }^{25} 7.5 \%$ of 1190 subjects older than 45 years without previously known liver disease who underwent medical check-ups had LS values $>8 \mathrm{kPa}$ in TE (suggestive of stage $\geq \mathrm{F} 2$ ), while $0.7 \%$ had LS values $>13 \mathrm{kPa}$ (suggestive of cirrhosis). 


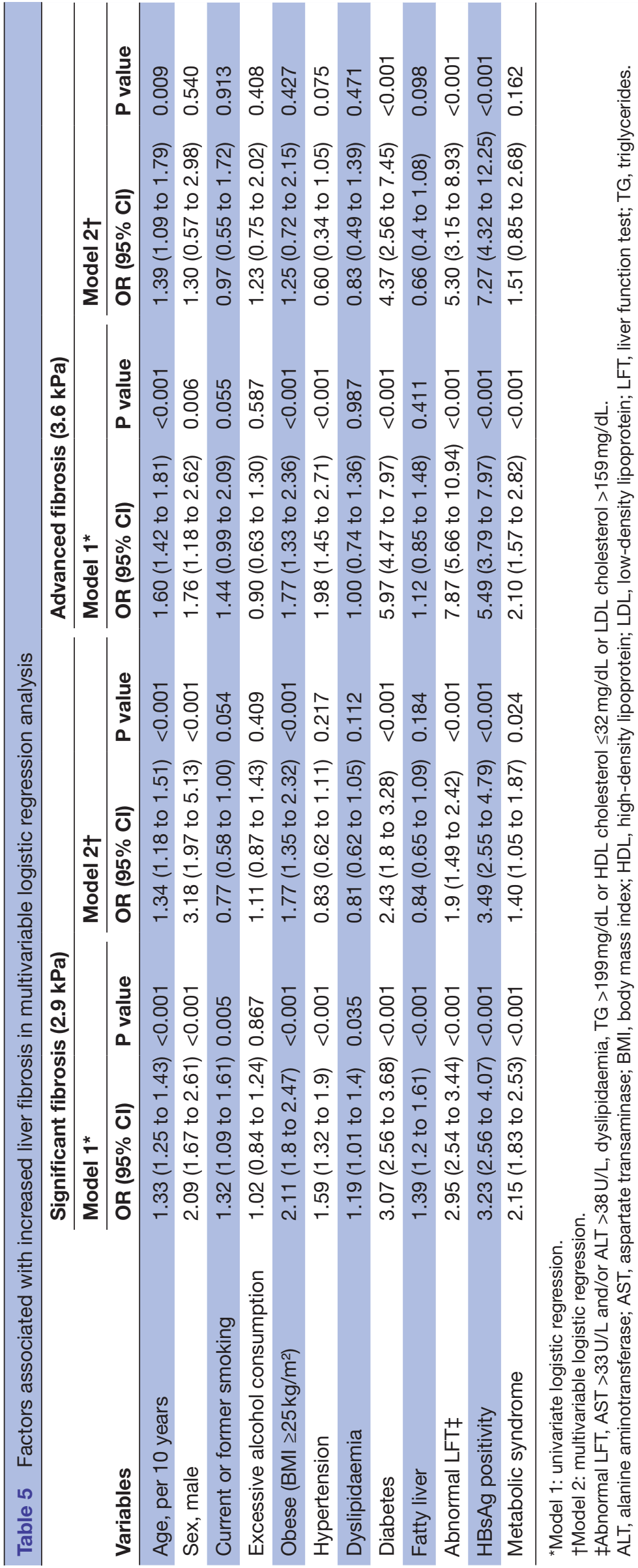




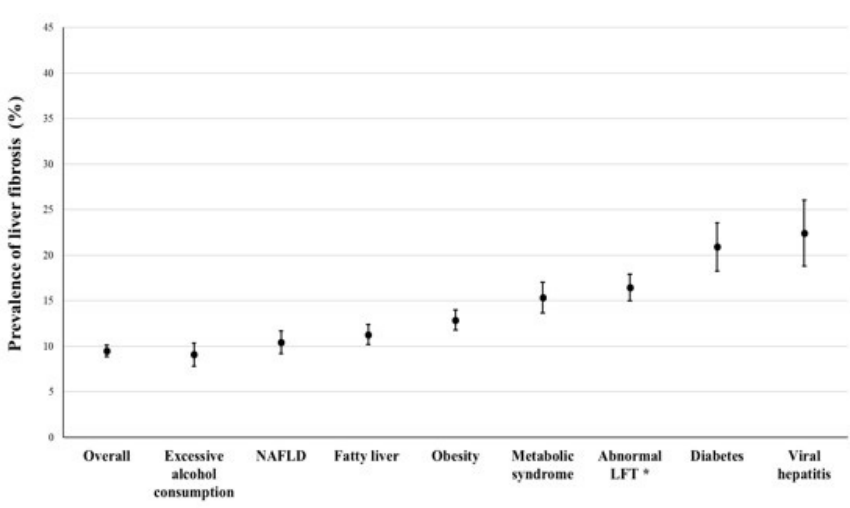

Figure 4 Mean and $95 \% \mathrm{Cl}$ values for the prevalence of liver fibrosis ( $\geq \mathrm{F} 2$ ) using MRE according to risk factors. *Abnormal LFT: AST>33U/L and/or ALT >38 U/L. ALT, alanine aminotransferase; AST, aspartate transaminase; LFT, liver function test; MRE, magnetic resonance elastography; NAFLD, non-alcoholic fatty liver disease.

The prevalence of significant liver fibrosis in the current study population ranged from $9.5 \%$ to $2.6 \%$ for cut-off LS values of 2.90 and $3.60 \mathrm{kPa}$, respectively. The prevalence of the advanced liver fibrosis using Fibrosis-4 Index with cut-off $\geq 2.67$ was $2.9 \%$ in the current study population (data not shown). We used MRE as a screening tool for liver fibrosis, which provides a highly accurate measurement of LS non-invasively. MRE is characterised by high interobserver reliability and it overcomes limitations of interpreting TE findings due to obesity or ascites, making it highly applicable. ${ }^{7-10}$ Xiao et $a l^{26}$ reported that the diagnostic accuracy of MRE was significantly higher than that of TE for both cirrhosis and significant fibrosis. However, very few studies have investigated the prevalence of liver fibrosis using MRE in the general population. Huwart et $a l^{20}$ proposed a cut-off LS value of $2.5 \mathrm{kPa}$ for significant fibrosis $(\geq F 2)$ in patients with suspicion of chronic liver disease who underwent MRE and liver biopsy. Moreover, Loomba $e t a t^{21}$ proposed a cut-off value of $3.63 \mathrm{kPa}$ for advanced fibrosis $(\geq \mathrm{F} 3)$ in non-alcoholic fatty liver disease (NAFLD). Applying these cut-offs for liver fibrosis to our results suggests that $9.5 \%$ of Korean general population has $\geq$ significant liver fibrosis, including $2.6 \%$ having advanced liver fibrosis. This finding suggests that $2.6 \%$ of the Korean general population has an increased risk of mortality, predominantly from cardiovascular and liverrelated diseases.

The prevalence of significant liver fibrosis increased with age in both sexes. Older age was associated with liver fibrosis in the current study, which is consistent with the findings of previous studies. ${ }^{27-29}$ The pathophysiology of increased LS in the aged population has been proposed. The number and volume of individual hepatocytes decreased with a decline of the hepatic blood flow with ageing, which may increase the LS. ${ }^{30}$ Reduced collagenolytic activity of matrix metalloproteinases might also increase the accumulation of collagen and liver fibrosis in aged livers. ${ }^{31}$ Moreover, cellular and molecular mechanisms regulating hepatic regeneration are affected by ageing. ${ }^{32}$

The current study included HBsAg-positive subjects, which revealed that $\mathrm{HBsAg}$ positivity was a strong predictor of $\geq$ significant liver fibrosis. The prevalence rates of carriers of the hepatitis $B$ virus (HBV) in their $40 \mathrm{~s}$ and $50 \mathrm{~s}$ (who comprised $60 \%$ of our subjects) were reported to be $4 \%-5 \%,{ }^{33}$ while it was only $0.1 \%$ among those younger 19 years who have gotten vaccinations against the HBV at their perinatal period in Korea. This finding suggests that HBsAg positivity was still important potential risk for liver fibrosis in our population, whose mean age was $46.9 \pm 10.5$ years.

Moreover, liver fibrosis was associated with T2DM as well as metabolic syndrome and obesity; these risk factors are also predictors of NAFLD. ${ }^{34}$ NAFLD is a frequent finding in patients with T2DM due to these two conditions sharing the underlying pathogenic mechanism of insulin resistance. ${ }^{35}$ The prevalence of $\geq$ significant liver fibrosis in patients with T2DM was highest among risk groups other than HBsAg-positive group in our population. T2DM was a strong predictor of liver fibrosis, especially at the advanced stage. Considering the ageing population and the increasing prevalence of diabetes, a potentially modifiable risk factor such as hyperglycaemia should be targeted early for detecting insulin resistance in prevention of liver fibrosis. While a more aggressive course of NAFLD and higher risk of cirrhosis have been reported in patients with T2DM and NAFLD,${ }^{36}$ the risk of advanced liver disease was present even in newly diagnosed patients with diabetes. ${ }^{37}$ These findings suggest the need for early screening of liver fibrosis in T2DM, perhaps at the time of the T2DM diagnosis in order to prevent further damage.

In this current study, alcohol consumption was not associated with liver fibrosis. Simple hepatic steatosis occurs in most subjects who ingest excessive amounts of alcohol or food. However, only a small percentage of these individuals will develop advanced liver fibrosis or cirrhosis. Toshikuni $e t a l^{38}$ explained that the disease progression may be caused by environmental-host interactions such as age, gender, metabolic syndrome, ethnicity and genetic variant. Furthermore, the development and progression of alcoholic liver disease are different according to the amount of alcohol intake, type of alcoholic beverage and drinking patterns. We could not assess the details as the alcoholic history was obtained from the self-reported questionnaire including the amount of alcohol intake. In addition, there was overlap between alcohol consumption and metabolic disorders in many individuals, particularly in men. ${ }^{39}$ There is a possibility that the metabolic factors may statistically offset the effect of alcohol on the liver fibrosis in our study.

Our study has some limitations. First, no histological information on subjects assumed to have significant liver fibrosis was analysed since liver biopsies 
are not usually justified to confirm the histological diagnosis of liver disease in asymptomatic health examinees. Second, selection bias associated with the reasons for undergoing health check-ups including MRE might have been present. MRE was additionally performed in the subject who chose MRE examination voluntarily during health check-ups. There was a possibility that those who have more concern for their hepatic condition had an MRE examination. Third, the study subjects comprised a higher proportion of men than women. Men tend to have more concerns for hepatic condition than women in Korea, which may also cause selection bias. Nevertheless, 1694 women were included, which should have been sufficient for ensuring adequate statistical power. Fourth, the study had a cross-sectional design, and so further studies are needed to track the changes in liver fibrosis after applying interventions and to monitor long-term outcomes.

In conclusion, the prevalence of significant liver fibrosis (including advanced liver fibrosis) was high in the present asymptomatic general population. The prevalence was especially high in the individuals with risk factors such as older age, male sex, obesity, T2DM, abnormal LFT, HBsAg positivity and metabolic syndrome. These findings suggest that screening of liver fibrosis should be considered in the asymptomatic general population, especially in individuals with risk factors in order to prevent the progression of liver fibrosis and reduce liver-related complications and mortality.

Acknowledgements The authors thank the Central Data Center at Korea Association of Health Promotion for collecting health information data.

Contributors All of the authors participated in designing this study. SC, EK and JC performed data collection. SK undertook the statistical analyses. E-HN, SC, $\mathrm{H}-\mathrm{IC}$ and SK analysed and interpreted the data. E-HN wrote the first draft of the manuscript, which was reviewed by all of the other authors, who also provided further contributions and suggestions.

Funding The authors have not declared a specific grant for this research from any funding agency in the public, commercial or not-for-profit sectors.

Map disclaimer The depiction of boundaries on this map does not imply the expression of any opinion whatsoever on the part of BMJ (or any member of its group) concerning the legal status of any country, territory, jurisdiction or area or of its authorities. This map is provided without any warranty of any kind, either expressed or implied.

\section{Competing interests None declared.}

Patient and public involvement Patients and/or the public were not involved in the design, or conduct, or reporting, or dissemination plans of this research.

\section{Patient consent for publication Not required}

Ethics approval This study was approved by the Institutional Review Board of the Korea Association of Health Promotion (approval no: 130750-202009-HR-016).

Provenance and peer review Not commissioned; externally peer reviewed.

Data availability statement No data are available.

Open access This is an open access article distributed in accordance with the Creative Commons Attribution Non Commercial (CC BY-NC 4.0) license, which permits others to distribute, remix, adapt, build upon this work non-commercially, and license their derivative works on different terms, provided the original work is properly cited, appropriate credit is given, any changes made indicated, and the use is non-commercial. See: http://creativecommons.org/licenses/by-nc/4.0/.
ORCID iD

Eun-Hee Nah http://orcid.org/0000-0003-0637-4364

\section{REFERENCES}

1 GBD 2013 Mortality and Causes of Death Collaborators. Global, regional, and national age-sex specific all-cause and causespecific mortality for 240 causes of death, 1990-2013: a systematic analysis for the global burden of disease study 2013. Lancet 2015;385:117-71.

2 Schuppan D, Afdhal NH. Liver cirrhosis. Lancet 2008;371:838-51.

3 Lee YA, Wallace MC, Friedman SL. Pathobiology of liver fibrosis: a translational success story. Gut 2015;64:830-41.

4 Niederau C, Lange S, Heintges T, et al. Prognosis of chronic hepatitis C: results of a large, prospective cohort study. Hepatology 1998;28:1687-95.

5 Ginès P, Graupera I, Lammert F, et al. Screening for liver fibrosis in the general population: a call for action. Lancet Gastroenterol Hepatol 2016;1:256-60.

6 Williams R, Aspinall R, Bellis M, et al. Addressing liver disease in the UK: a blueprint for attaining excellence in health care and reducing premature mortality from lifestyle issues of excess consumption of alcohol, obesity, and viral hepatitis. Lancet 2014;384:1953-97.

7 Venkatesh SK, Yin M, Ehman RL. Magnetic resonance elastography of liver: technique, analysis, and clinical applications. J Magn Reson Imaging 2013;37:544-55.

8 Hsu C, Caussy C, Imajo K, et al. Magnetic resonance vs transient elastography analysis of patients with nonalcoholic fatty liver disease: a systematic review and pooled analysis of individual participants. Clin Gastroenterol Hepatol 2019;17:630-7.

9 Wang Q-B, Zhu H, Liu H-L, et al. Performance of magnetic resonance elastography and diffusion-weighted imaging for the staging of hepatic fibrosis: a meta-analysis. Hepatology 2012;56:239-47.

10 Chen J, Talwalkar JA, Yin M, et al. Early detection of nonalcoholic steatohepatitis in patients with nonalcoholic fatty liver disease by using Mr elastography. Radiology 2011;259:749-56.

11 Harman DJ, Ryder SD, James MW, et al. Direct targeting of risk factors significantly increases the detection of liver cirrhosis in primary care: a cross-sectional diagnostic study utilising transient elastography. BMJ Open 2015;5:e007516.

12 Morling JR, Fallowfield JA, Guha IN, et al. Using non-invasive biomarkers to identify hepatic fibrosis in people with type 2 diabetes mellitus: the Edinburgh type 2 diabetes study. $J$ Hepatol 2014;60:384-91.

13 Williamson RM, Price JF, Hayes PC, et al. Prevalence and markers of advanced liver disease in type 2 diabetes. QJM 2012;105:425-32.

14 Nahon P, Kettaneh A, Tengher-Barna I, et al. Assessment of liver fibrosis using transient elastography in patients with alcoholic liver disease. J Hepatol 2008;49:1062-8.

15 Farrell GC, Chitturi S, Lau GKK, et al. Guidelines for the assessment and management of non-alcoholic fatty liver disease in the AsiaPacific region: Executive summary. J Gastroenterol Hepatol 2007;22:775-7.

16 Yin M, Talwalkar JA, Glaser KJ, et al. Assessment of hepatic fibrosis with magnetic resonance elastography. Clin Gastroenterol Hepatol 2007;5:1207-13.

17 Rockey DC, Bissell DM. Noninvasive measures of liver fibrosis. Hepatology 2006;43:S113-20.

18 Hines CDG, Bley TA, Lindstrom MJ, et al. Repeatability of magnetic resonance elastography for quantification of hepatic stiffness. $J$ Magn Reson Imaging 2010;31:725-31.

19 Chen J, Talwalkar JA, Yin M, et al. Early detection of nonalcoholic steatohepatitis in patients with nonalcoholic fatty liver disease by using Mr elastography. Radiology 2011;259:749-56.

20 Huwart L, Sempoux C, Salameh N, et al. Liver fibrosis: noninvasive assessment with Mr elastography versus aspartate aminotransferase-to-platelet ratio index. Radiology 2007;245:458-66.

21 Loomba R, Wolfson T, Ang B, et al. Magnetic resonance elastography predicts advanced fibrosis in patients with nonalcoholic fatty liver disease: a prospective study. Hepatology 2014;60:1920-8.

22 Lee KN, Yoon JH, Cho HI. A study on reference values from health checkup data of Korea association of health promotion by indirect method (a study on standardization of reference values among laboratories of Korea association of health promotion II). J Lab Med Qual Assur 2009;31:309-15.

23 Wong VW-S, Chu WC-W, Wong GL-H, et al. Prevalence of nonalcoholic fatty liver disease and advanced fibrosis in Hong Kong Chinese: a population study using proton-magnetic resonance spectroscopy and transient elastography. Gut 2012;61:409-15. 
24 Caballería L, Pera G, Arteaga I, et al. High prevalence of liver fibrosis among European adults with unknown liver disease: a population-based study. Clin Gastroenterol Hepatol 2018;16:1138-45.

25 Roulot D, Costes J-L, Buyck J-F, et al. Transient elastography as a screening tool for liver fibrosis and cirrhosis in a community-based population aged over 45 years. Gut 2011;60:977-84.

26 Xiao H, Shi M, Xie Y, et al. Comparison of diagnostic accuracy of magnetic resonance elastography and Fibroscan for detecting liver fibrosis in chronic hepatitis $B$ patients: a systematic review and meta-analysis. PLoS One 2017;12:e0186660.

27 Hoare M, Das T, Alexander G, Ageing AG. Ageing, telomeres, senescence, and liver injury. J Hepatol 2010;53:950-61.

28 Salles N, Dussarat P, Foucher J, et al. Non-Invasive evaluation of liver fibrosis by transient elastography and biochemical markers in elderly inpatients. Gastroenterol Clin Biol 2009;33:126-32.

29 Sirli R, Sporea I, Tudora A, et al. Transient elastographic evaluation of subjects without known hepatic pathology: does age change the liver stiffness? J Gastrointestin Liver Dis 2009;18:57-60.

30 Wynne HA, James OF. The ageing liver. Age Ageing 1990;19:1-3.

31 Gagliano N, Arosio B, Grizzi F, et al. Reduced collagenolytic activity of matrix metalloproteinases and development of liver fibrosis in the aging rat. Mech Ageing Dev 2002;123:413-25.
32 Schmucker DL, Sanchez H. Liver regeneration and aging: a current perspective. Curr Gerontol Geriatr Res 2011;2011:1-8.

33 Ministry of Health and Welfare (KR). Korea center for disease control and prevention. Korea health statistics 2018: Korea National health and nutrition examination survey (KNHANES VII-3). Cheongju: Korea: Korea Center for Disease Control and Prevention, 2019.

34 Angulo P, Keach JC, Batts KP, et al. Independent predictors of liver fibrosis in patients with nonalcoholic steatohepatitis. Hepatology 1999;30:1356-62.

35 Cusi K. Role of insulin resistance and lipotoxicity in non-alcoholic steatohepatitis. Clin Liver Dis 2009;13:545-63.

36 Adams LA, Sanderson S, Lindor KD, et al. The histological course of nonalcoholic fatty liver disease: a longitudinal study of 103 patients with sequential liver biopsies. J Hepatol 2005;42:132-8.

37 Porepa L, Ray JG, Sanchez-Romeu P, et al. Newly diagnosed diabetes mellitus as a risk factor for serious liver disease. CMAJ 2010;182:E526-31.

38 Toshikuni N, Tsutsumi M, Arisawa T. Clinical differences between alcoholic liver disease and nonalcoholic fatty liver disease. World $\mathrm{J}$ Gastroenterol 2014;20:8393-406.

39 Völzke H. Multicausality in fatty liver disease: is there a rationale to distinguish between alcoholic and non-alcoholic origin? World $J$ Gastroenterol 2012;18:3492-501. 